\title{
LOS DEBERES ESCOLARES. UN ANÁLISIS SISTEMATIZADO CON ESPECIAL REFERENCIA AL CASO ESPAÑOL
}

\author{
Rafael Feito Alonso \\ Universidad Complutense de Madrid
}

\begin{abstract}
RESUMEN: La cuestión de los deberes ha sido especialmente controvertida en España durante los últimos años a raíz de las protestas planteadas por parte de las familias con relación al exceso de tiempo que sus hijos tienen que dedicar a tal actividad. El principal referente en la investigación sobre esta cuestión es Cooper. El problema fundamental que, desde la perspectiva de hoy, nos presenta su trabajo es que las investigaciones en las que basa su metaanálisis fueron realizadas hace ya más de una década. En todo caso, de sus escritos se pueden extraer varias lecciones muy claras: hay una moderada correlación entre la realización de deberes y los resultados escolares en Secundaria pero ninguna en Primaria, más de dos horas de deberes al día resultan contraproducentes y los padres no deben participar en su realización. En España, algo sabemos gracias a los informes PISA y TIMSS y a algunos informes realizados a instancia de consejos escolares autonómicos. Lo que aquí se observa es que nuestros estudiantes realizan muchos deberes y que estos son difíciles y nada creativos. Pese a ello, la inmensa mayoría, tanto del alumnado como del profesorado y de los padres, los considera necesarios. El tipo de deberes que han de realizar nuestros escolares se explica por el tipo de docencia y el currículo imperante en nuestra escuela.
\end{abstract}

PALABRAS CLAVE: deberes escolares, familia, currículo, innovación escolar.

\section{SCHOOL HOMEWORK. A SYSTEMATIC ANALYSIS WITH SPECIAL REFERENCE TO THE SPANISH CASE}

\footnotetext{
ABSTRACT: The issue of homework has been particularly controversial in Spain in recent years as a result of the protests raised by families regarding the excessive amount of time their children have to devote to this activity. The main reference in the research about this issue is Cooper. What Cooper does is a meta-analysis. The main problem is that this research was carried out more
} 
than a decade ago. In any case, several very clear lessons can be drawn from his analysis: there is a moderate correlation between homework and school results in Secondary Education but none in Primary Education. More than two hours of homework per day are counterproductive and parents should not participate in its completion. In the case of Spain it is possible to resort to PISA and TIMSS data and to some reports being issued at the request of school councils from some Spanish regions. What we see here is that our students do a lot of homework which is for the most part difficult and uncreative. In spite of this, the vast majority of students, teachers and parents consider them to be necessary. The type of homework that our students have to do is explained by the hegemonic teaching style and the huge prevailing curriculum in Spain.

KEYWORDS: Homework, family, school knowledge, educational innovation.

Recibido: 08/07/2018

Aceptado: 27/02/2019

Correspondencia: Rafael Feito Alonso, Dpto. de Sociología III, Facultad de Ciencias Políticas y Sociología, Universidad Complutense de Madrid, Campus de Somosaguas, 28023 Madrid. Email: rfeito@cps.ucm.es.

La cuestión de los deberes ha sido especialmente polémica en España en los últimos años. Ya en 2013, la Confederación Española de Asociaciones de Padres de Alumnos (CEAPA) denunció la enorme cantidad de tarea para casa que tenían que realizar algunos alumnos. En noviembre de 2016, esta organización promovió una campaña en protesta, no tanto contra los deberes como contra su exceso (CEAPA, 2016) y cuya reivindicación consistía en solicitar que el alumnado no tuviera que hacerlos durante los fines de semana. En 2015, Eva Bailén, madre de varios alumnos, lanzó una campaña en change.org en este mismo sentido, la cual tuvo un amplísimo eco en muy diferentes medios de comunicación (produciendo incluso un vídeo viral) y dio lugar a que ella misma publicara un libro con el contundente título de Cómo sobrevivir a los deberes de tu hijo (2015). Justamente, tal exceso de tareas para casa ha dado lugar a quejas de padres ante los Defensores del Pueblo de algunas comunidades autónomas, los cuales, a su vez, se dirigieron a los Consejos Escolares de sus respectivas comunidades. En ocasiones, la respuesta de estos Consejos ha dado lugar a la realización de informes sobre el estado de la cuestión, tal y como veremos en este artículo (en concreto, son los realizados por los Consejos Escolares de Castilla-León y de Navarra). Igualmente, es de destacar el informe colectivo publicado por la Comunidad de Madrid (CAM, 2017) en el que se recogen experiencias sobre los deberes en diferentes centros educativos y algunos análisis de datos secundarios a partir del PISA y la rigurosa monografía realizada para la Consellería de Cultura, Educacion e Ordenacion Universitaria de Galicia (2017). 
Como contrapunto a esta campañas, el presidente de la otra gran federación de padres en España, la Confederación Católica Nacional de Padres de Familia y Padres de Alumnos (CONCAPA), Pedro José Caballero (ABC, 2017), consideró que "las tareas para casa ayudan a reforzar lo aprendido en clase" y que "los deberes pueden ser también un momento de afianzar la identidad familiar, cuando padres e hijos trabajan conjuntamente, teniendo claro que no se trata de hacerles los deberes, sino de caminar juntos en el desarrollo escolar y familiar de los hijos".

El debate sobre los deberes procede sobre todo del hecho de que hay familias que detectan que sus hijos hacen demasiados deberes o tienen que dedicar un tiempo desmesurado a su realización. De hecho, y de acuerdo con un sondeo realizado por Metroscopia para el diario El País (Álvarez, 2016), el 61\% los considera excesivos, el $27 \%$ adecuados, un magro $3 \%$ insuficientes y el resto o no sabe o no contesta. La reflexión sobre tal exceso de tiempo ha propiciado la discusión sobre si estas tareas tienen sentido y si, en realidad, responden a una concepción obsoleta de la escuela.

A esto hay que añadir la cuestión de la posible gran dificultad de los deberes y la implicación o no de los padres en su realización. En una entrevista, Andreas Schleicher (2017) señalaba que los deberes -a los cuales considera siempre importantes- en España son difíciles y rutinarios y frecuentemente requieren de la ayuda de los padres, y añadía que "usando el tiempo de manera productiva, los estudiantes españoles no harían más deberes que en otros países".

En este artículo vamos a ver, en primer lugar, qué dice la investigación educativa internacional (fundamental, pero no exclusivamente, de los Estados Unidos) sobre el tema, qué podemos decir sobre esta cuestión en España (a partir de datos de los informes PISA (Programme for International Student Assessment) y TIMSS (Trends in International Mathematics and Science Study), así como de diferentes investigaciones y de los informes antes citados realizados por algunos consejos escolares autonómicos), su regulación legal y normativa, y en qué consisten -y en qué podrían consistirlos deberes.

\section{LO QUE DICE LA INVESTIGACIÓN INTERNACIONAL}

Sin ningún género de dudas, el autor más referenciado es Cooper (2007), quien ha realizado varios trabajos basados en metaanálisis (técnica consistente en sumar numerosos estudios como si equivalieran a uno solo), el último de los cuales fue publicado -en el ya lejano 2007- en su libro, de carácter más bien divulgativo, titulado The Battle Over Homework. En esta obra, suministra la definición más aceptada de los deberes: "tareas que los profesores mandan a los alumnos, las cuales han de ser realizadas fuera del tiempo docente (no instruccional)".

Entre otras cosas, Cooper explica el carácter cíclico del debate social sobre los deberes. Hubo un importante consenso en torno a su necesidad y a que se les dedicara más tiempo cuando los Estados Unidos se vieron superados por sus más inmediatos competidores internacionales: la Unión Soviética en los años cincuenta con motivo 
de la carrera espacial (el Ilamado efecto Sputnik) y en los años ochenta por el mayor avance tecnológico de Japón (y que dio lugar al famoso informe A Nation at Risk). En ambos casos, se consideró que el retraso de Estados Unidos se debía a que su sistema educativo era menos exigente que el de sus competidores y que, entre otras cosas, el alumnado tendría que esforzarse más, lo que se traduciría en dedicar más tiempo a los deberes.

Cooper es universalmente conocido por la regla de los diez minutos, según la cual los deberes no deberían ocupar a los niños más de diez minutos al día (solo de lunes a jueves) en el primer curso de primaria, para ir añadiendo diez minutos por curso a medida que se avanza de año hasta un máximo de dos horas diarias en Secundaria (más tiempo es inútil).

Una cuestión fundamental es la de la implicación de los padres en las tareas. En su libro sobre los deberes, Cooper (2007) señala que tal implicación puede tener consecuencias negativas, ya que los padres presionan a sus hijos para que acaben los deberes y pueden ser exageradamente exigentes, de modo que les generan confusión. Sin embargo, poco después Cooper en un artículo publicado con otros dos autores (Patall, Cooper \& Robinson, 2008) indica que los estudiantes pueden considerar más agradables los deberes si sus padres participan de ellos, ya que cuando estos se implican los alumnos señalan estar más atentos y tener una mejor disposición para hacerlos.

Cooper defiende la idea de que los deberes contribuyen a desarrollar la responsabilidad personal del alumnado. Sin embargo, en un relativamente reciente informe del Parlamento de Victoria (Australia) en el que se recogen las intervenciones de destacados especialistas se dice lo siguiente:

Hay que tener en cuenta que la mayor parte de la evidencia sobre los efectos positivos de los deberes en el desarrollo de habilidades no académicas como la responsabilidad, la autodisciplina y la motivación es intuitiva o anecdótica, ya que se ha hecho poca investigación al respecto." (Education and Training Committee, 2014)

De acuerdo con Cooper, los deberes en Primaria son poco productivos, pero no así en Secundaria.

Para los estudiantes de Secundaria, por otro lado, el efecto de los deberes puede ser impresionante. De hecho, en comparación con otras técnicas de instrucción, los deberes pueden producir un efecto positivo superior al promedio en el desempeño de los adolescentes en la escuela. Pero una vez más, incluso para los estudiantes mayores, demasiado de algo bueno puede no ser tan bueno en absoluto. La evidencia correlacional sugiere que los estudiantes de Secundaria que dedican más de dos horas a los deberes al día no logran mejores resultados que quienes emplean menos de dos horas. (Cooper, 2007: 65).

En realidad, y como ya criticara Kohn (2006) -quizás el investigador de más renombre entre quienes se oponen a los deberes-, lo que Cooper encuentra es 
un cierto grado de correlación entre los deberes y los resultados escolares. Pero, correlación no es causalidad. Por otra parte, Kohn señala que "Cooper incluyó diecisiete informes de investigación que contenían un total de cuarenta y ocho comparaciones entre estudiantes que hicieron deberes y otros que no. Alrededor del 70 por ciento de ellos encontraron que los deberes se asociaban con un mayor rendimiento". También revisó las encuestas que intentaban correlacionar los resultados de las pruebas de los estudiantes con la cantidad de tareas que hacían. Cuarenta y tres de cincuenta correlaciones fueron positivas, aunque el efecto general no fue particularmente grande: los deberes representaban menos del 4 por ciento de las diferencias en el rendimiento de los estudiantes. Peor aún, la mayoría de los estudios incluidos en la revisión tenían "defectos metodológicos" tan graves que planteaban dudas sobre la validez de cualquier conclusión basada en ellos (Kohn, 2007).

En su metaánalisis, Hattie (2009: 17) indica que los beneficios para los estudiantes de Secundaria inferior son débiles, ya que tan sólo alrededor del 20 por ciento de los estudiantes en los grados siete a nueve (equivalente a los tres primeros cursos de la ESO) obtienen mejores resultados como consecuencia de los deberes. Los beneficios para los estudiantes de Secundaria Superior son mayores. En términos más técnicos, el efecto típico de los deberes es $\mathrm{d}=0.29$, un índice muy reducido. Tal y como aclara el propio Hattie (2009: 8), se trataría de una diferencia similar a la que hay entre una persona que midiera 1,82 metros (la que hace deberes) y otra con una estatura de 1,80 (la que no los hace). Como resumía certeramente Walker (2012), parece haber consenso en que los beneficios de los deberes para los alumnos de escuela primaria son inexistentes, limitados para los de Secundaria Inferior y razonables para los de Secundaria Superior.

A partir de aquí resulta fácilmente comprensible la perplejidad que manifestaba Hallam (2006) sobre la enorme cantidad de problemas metodológicos que plantea la investigación sobre los deberes.

En primer lugar, es difícil aislar los efectos de los deberes de los muchos otros factores que afectan a los resultados del aprendizaje, por ejemplo, la calidad de la enseñanza, el ethos escolar y el rendimiento previo de los alumnos. En segundo lugar, evaluar la cantidad de tiempo dedicado a los deberes es problemático porque las estimaciones varían dependiendo de si los hacen los alumnos, los padres o los profesores. En tercer lugar, rara vez se tienen en cuenta la calidad o el tipo de deberes. En cuarto lugar, los estudios adoptan diferentes medidas de eficacia, en distintas escalas temporales, y rara vez consideran el rendimiento académico o los resultados afectivos del aprendizaje, por ejemplo, la motivación o las actitudes hacia la escuela. Por último, la investigación ha tendido a concentrarse en los deberes en los que los resultados del aprendizaje pueden medirse cuantitativamente, por ejemplo, en Matemáticas, ignorando, en gran medida, otros ámbitos, o los deberes en los que el rendimiento debe evaluarse cualitativamente. Por estas razones, es difícil interpretar y generalizar los resultados de gran parte de la investigación. 
Mayoritariamente, la investigación se ha centrado en el tiempo dedicado a los deberes y el tiempo por sí solo no es un buen predictor del rendimiento escolar. En los últimos años ha surgido una nueva generación de estudios sobre los deberes. Investigadores como Trautwein (2007) introdujeron la cuestión de la actitud ante los deberes. Un estudiante podría dedicar mucho tiempo a los deberes porque se distrae con frecuencia. Y otra cuestión, no menos importante, es el hecho de realizar o no todas las tareas mandadas por el profesorado. Esto es lo que más recientemente plantearon Huiyong, F. et al (2017) en un artículo en el que revisaban la literatura sobre los deberes publicada entre 1986 y 2015 . Tienen en cuenta el hecho de hacer o no los deberes en su totalidad, el esfuerzo en su realización y el tiempo dedicado para ello. Contrariamente a los resultados obtenidos por Cooper, la relación entre los deberes y los resultados es mayor en Primaria que en Secundaria y ello, posiblemente, se debe a una mayor implicación de los padres en su realización.

A resultados similares llegaron, esta vez en el caso español, Valle et al. (2015) ${ }^{1}$ en un estudio en el que participaron 326 estudiantes pertenecientes a dos centros públicos de Educación Primaria de la provincia de A Coruña y en el que se analizó el rendimiento en Matemáticas y Lengua Inglesa. En él se analizó la relación entre deberes y rendimiento a partir de la "(a) cantidad de deberes realizados de los prescritos, (b) tiempo dedicado a la realización de los deberes y (c) gestión del tiempo empleado (aprovechamiento del tiempo), y tomando como criterio dos áreas curriculares teóricamente diferentes (Matemáticas y Lengua Inglesa)". De acuerdo con esta investigación "el rendimiento académico en los últimos cursos de Primaria (en las materias de Lengua Inglesa y Matemáticas) será mayor en la medida en que se realicen mayor número de deberes escolares de los prescritos, se aproveche mejor el tiempo utilizado para hacer los deberes y se dedique menos tiempo a la realización de esos deberes".

\section{2. ¿Qué sabemos sobre los deberes en EsPaña?}

A continuación, veremos qué se sabe sobre los deberes en España. Para ello se utilizarán las escasas investigaciones e informes sobre esta cuestión y se prestará especial atención al tiempo dedicado a estas tareas y las opiniones que merecen.

A la luz de informes internacionales como el PISA y el TIMSS queda claramente de manifiesto que España es de los países en que los alumnos dedican más tiempo a los deberes. Más abajo tenemos un gráfico del informe PISA de 2012. Pese a que, en la mayoría de los sistemas educativos, ha decrecido el tiempo dedicado a las tareas escolares, España sigue siendo uno de los países con más deberes, tal y como se puede ver en la Figura 1 (OECD, 2014).

1. Este y otros artículos sobre esta temática se pueden ver en la tesis doctoral de Irene Pan cuyo título es Deberes escolares, aprendizaje y rendimiento académico en estudiantes de educación primaria (2015). Disponible en https://ruc.udc.es/dspace/bitstream/handle/2183/16138/PanLopez_Irene_TD_2015. pdf? sequence $=4 \&$ isAllowed $=y$ 


\section{Los alumnos pasan mucho tiempo haciendo deberes, pero menos que en 2003}

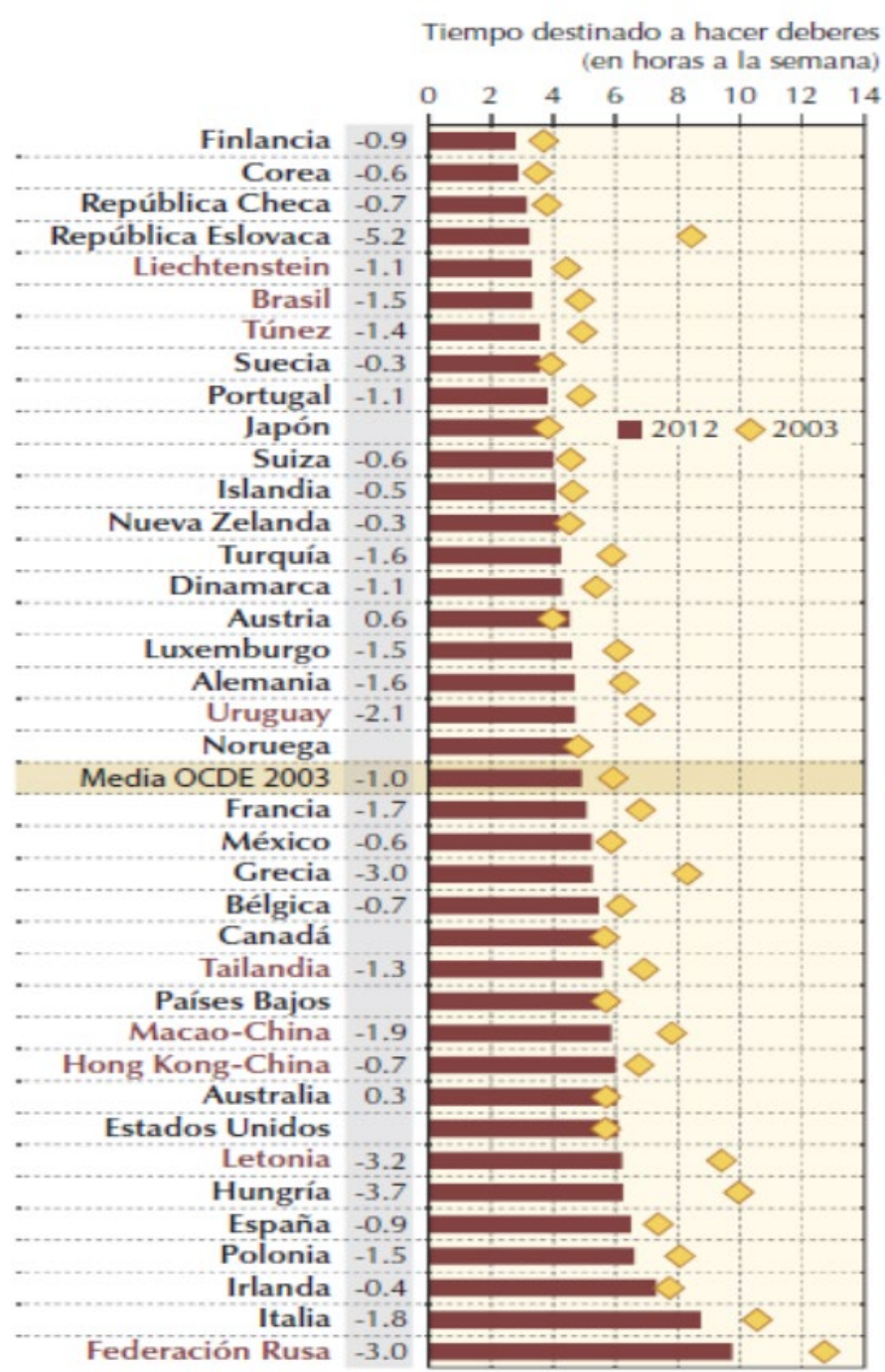

\section{Figura 1}

Spatarelu (2017), como se ve en la Figura 2, compara los tiempos dedicados a los deberes con los resultados obtenidos en esta prueba a partir de los datos de la edición del TIMSS de 2011 (en el que participaron alumnos de cuarto grado -diez años de edad- de treinta países). 


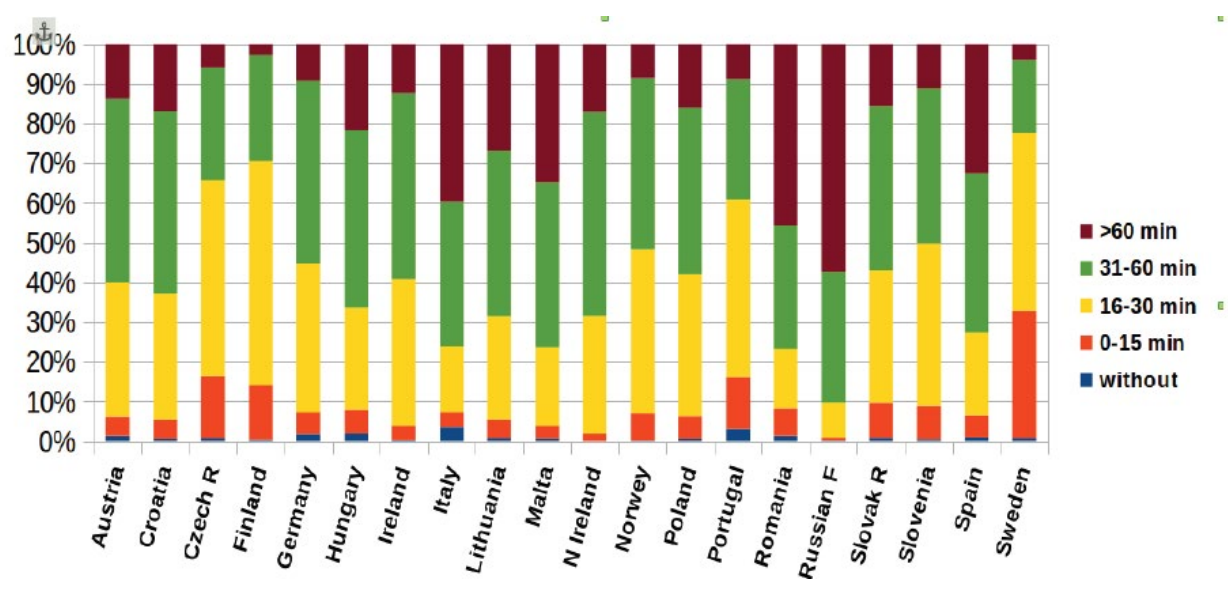

Figura 2

Como se puede observar, España junto con Italia, Rusia, Malta y Rumania, es el país en el que hay un mayor porcentaje de alumnos que dedica más de sesenta minutos diarios a los deberes. Sin embargo, tal y como se ve más abajo (Spatarelu, 2017), España obtiene, comparativamente, bajos resultados (al igual que sucede con los países en los que se emplea mucho tiempo en las tareas escolares).

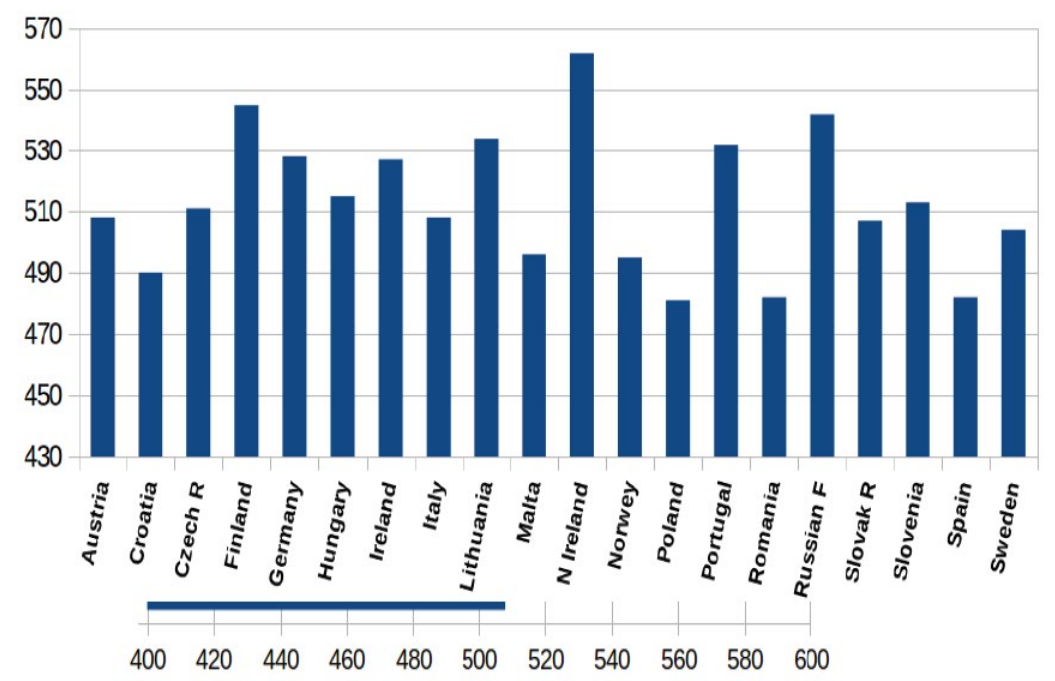

Figura 3

Sin embargo, conviene no perder de vista que cuando trabajamos con los datos de cada país individualmente considerado, los estudiantes que más tiempo dedican a las tareas son los que obtienen mejores resultados. 
El informe realizado para la Junta de Castilla-León (2017) muestra, igualmente un alto porcentaje de alumnado -tanto en la ESO como en Primaria- que dedica más de una hora diaria a los deberes.

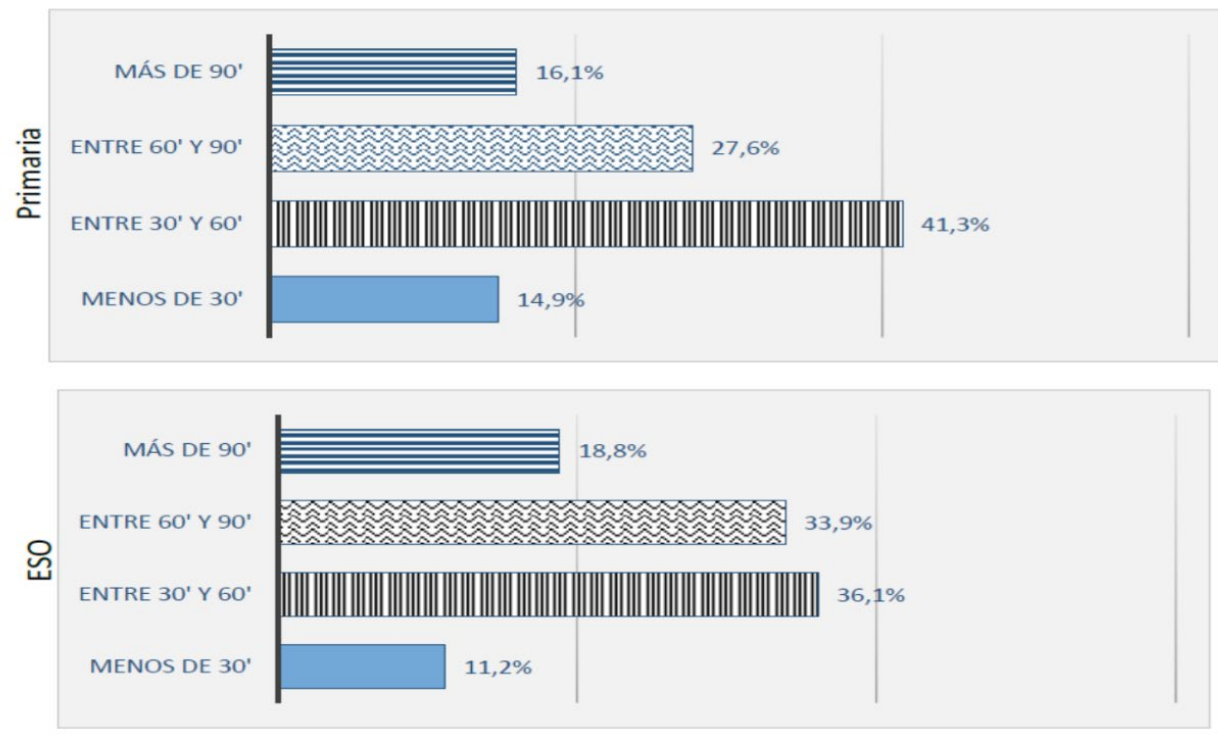

Figura 4

El informe de la Consellería de Educación de Galicia va más allá de la mera contabilización del tiempo dedicado a los deberes e introduce las variables de la cantidad de deberes realizados, su grado de aprovechamiento y cómo son percibidos por el alumnado.

\section{Cuadro 1}

\begin{tabular}{|l|c|c|c|c|c|c|c|c|c|}
\hline Colectivo & Datos & - & $30^{\circ}-$ & $60^{\circ}-$ & $90^{\circ}-$ & + de & Total & Media & D.T. \\
\hline Alumnado & Frec. & 184 & 315 & 154 & 45 & 20 & 718 & & \\
& $\%$ & 26 & 44 & 21 & 6 & 3 & 100 & 2.17 & 0.979 \\
\hline \multirow{2}{*}{ Familias } & Frec. & 67 & 191 & 102 & 47 & 30 & 437 & & \\
& $\%$ & 15 & 44 & 23 & 11 & 7 & 100 & 2.50 & 1.089 \\
\hline \multirow{2}{*}{ Profesorado } & Frec. & 93 & 104 & 21 & 5 & 0 & 223 & & \\
& $\%$ & 42 & 47 & 9 & 2 & 0 & 100 & 1.72 & 0.725 \\
\hline
\end{tabular}

Resultan Ilamativas las diferencias entre la percepción que tienen profesores, padres y alumnos con respecto al tiempo que consideran dedicar a las tareas escolares, tal y como se puede ver en el siguiente cuadro (Amiama, 2013). 
De los profesores entrevistados, ni uno solo considera que sus alumnos dediquen más de dos horas a los deberes y tan solo cinco (el dos por ciento de la muestra) creen que supongan más de noventa minutos. A casi la mitad (42\%) le parece que se solventan en menos de treinta minutos. Muy diferente es la percepción que tienen las familias y los alumnos. Solo el $15 \%$ de las primeras y el $27 \%$ de los segundos creen que las tareas impliquen menos de treinta minutos. Quizás por discrepancias como estas, desde otras latitudes, Sztabnik (2014) consideraba útil que el profesor hiciera él mismo los deberes para calcular el tiempo necesario para su realización.

El informe de la Junta de Castilla-León (2017) recoge las opiniones de los profesores, padres y alumnos sobre los deberes. El 85\% de los maestros que imparte clase en quinto curso de Educación Primaria opina que la inmensa mayoría de sus compañeros docentes son partidarios de los deberes escolares. Se constata que el $84 \%$ de las familias los considera útiles. Este dato contrasta con un sondeo realizado por Metroscopia (Álvarez, 2016) en el que se detecta que la mitad de los ciudadanos (que no necesariamente son padres de alumnos) los considera positivos y la otra mitad no. Es más, el 61\% cree que hay demasiados deberes. La Fundación de Ayuda contra la Drogadicción patrocinó una investigación sobre opiniones de asociaciones de padres y madres de alumnos o AMPA (Rubio, Sanmartín y Rodríguez, 2017) en la que se preguntaba, entre otras cuestiones, por los deberes. El 26,1\% está totalmente de acuerdo con que las tareas escolares han de realizarse diariamente, el 42,9\% mantiene una posición intermedia y el $26,7 \%$ no está nada de acuerdo. Las AMPA de los centros concertados son más favorables a los deberes que las de los públicos. Casi la mitad de estas organizaciones (42,9\%) considera que los deberes deberían hacerse en el aula dentro del horario escolar. Esta posición es mayoritaria entre las AMPA de clase baja (el 85,7\%). Sin embargo, entre las de clase media-alta el 30\% está en desacuerdo.

Igualmente, el informe de la Junta de Castilla-León detecta serias discrepancias entre las opiniones que sobre los deberes tienen los estudiantes de Primaria con respecto a los de Secundaria. A diferencia de los primeros, y tal y como puede verse más abajo en la Figura 5, la mayoría de estos últimos consideran aburridas, excesivas y difíciles las tareas escolares.

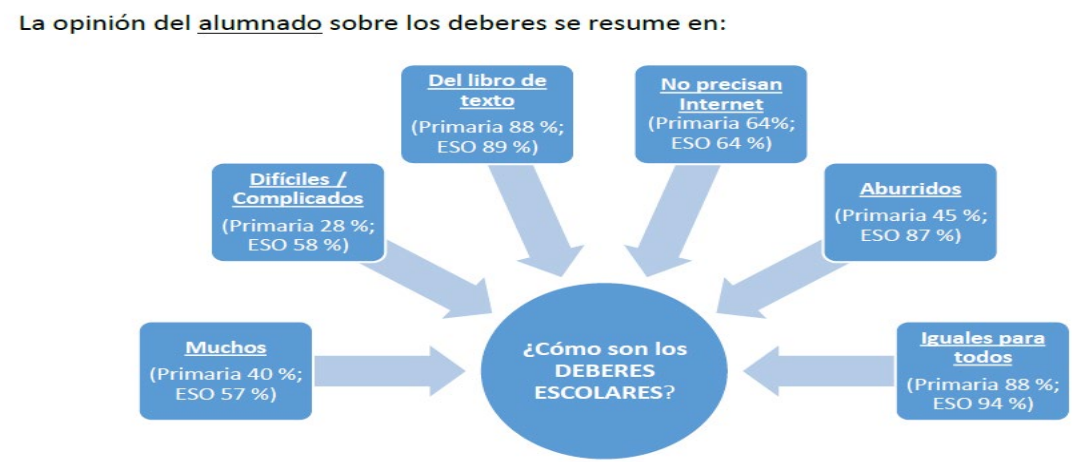

Figura 5 
Los alumnos del IES sobre el que escriben Arribas y Gil (2017: 105) están en la misma línea. Esto es lo que dicen sus estudiantes:

Los alumnos nos sentimos cansados. No hay momentos de desconexión. Los fines de semana, festivos y puentes tenemos deberes, incluso en las vacaciones de Navidad o Semana Santa. Las vacaciones de verano tampoco se salvan, en algunas asignaturas nos mandan cuadernillos para el verano. Nada más empezar las clases en septiembre tenemos los exámenes de evaluación inicial.

El informe realizado por el Consejo Escolar de Navarra (2015) también detecta que los estudiantes de Secundaria (en concreto, el 50,5\% de ellos) consideran que les resulta difícil hacer las tareas solos.

No es de extrañar que esta circunstancia se traduzca en un serio malestar entre el alumnado. De acuerdo con el informe sobre las diferencias socioeconómicas y de género en la salud y el bienestar de los jóvenes de la Organización Mundial de la Salud (World Health Organization, 2016) se detecta que en España, desde la edad de 11 años, el $34 \%$ de los niños y el 25\% de las niñas declara sentirse presionado por las tareas escolares. A medida que se avanza en edad la cosa empeora, de modo que a los trece años tales porcentajes suben, respectivamente, a un $53 \%$ y a un $55 \%$. A los 15 años la mayoría se siente estresada (lo que ocurre con el 60\% de los niños y el $70 \%$ de las niñas). La situación puede ser peor en las escuelas de clase media alta. En una investigación sobre este tipo de centros, los estudiantes describen sus deberes como una actividad que estructura sus días. "En lugar de aprender y comprometerse profundamente, estos estudiantes dicen dedicarse a "hacer lo mínimo para obtener buenas notas", y expresan su voluntad de sacrificar su salud e integridad académica a fin de completar con éxito su trabajo para mantener o aumentar su estatus de logro En estos climas escolares competitivos, el aprendizaje se ha convertido en un objetivo secundario. En cambio, el trabajo duro de los estudiantes y el estrés que crea son aceptados como necesarios para obtener las credenciales necesarias para tener éxito en un clima competitivo" (Galloway, Conner y Pope, 2013). En este sentido, Trautwein (2007: 372) señalaba que buena parte de la investigación no controla variables que pueden llevar a confusión.

Por ejemplo, los estudiantes que asisten a un curso avanzado de matemáticas o a una escuela de élite pueden dedicar más tiempo a las tareas de matemáticas que los estudiantes matriculados en un curso básico o en una escuela de nivel inferior. Del mismo modo, se podrían hacer más deberes en escuelas de alta calidad a las que asisten estudiantes de orígenes privilegiados.

Muchos padres y madres se implican en las tareas de sus hijos -quizás hasta el extremo de que muchos progenitores puedan llegar a considerar que el profesor les suspende a ellos en lugar de a sus retoños-. En la investigación sobre padres e hijos en España, Meil (2006) señalaba que el 77\% de los padres declaraba ayudar a sus hijos con los deberes (a lo que hay que añadir que en un 5\% de casos tal ayuda la suministraba un hermano del alumno y en otro $12 \%$ se trataba de un profesor particular) frente a un $23 \%$ que indicaba que sus hijos no precisaban de ayuda. Si nos vamos 
a grupos de edad, solo un $9 \%$ de padres y madres de niños y niñas de entre diez y doce años declaraba que estos no precisaban ayuda. En el grupo de entre los 15 y 16 años este porcentaje subía al 32\%. En el estudio de Pérez-Díaz, Rodríguez y Fernández (2009) se indicaba que, en 2008, el 56,5\% de los padres y madres siempre o bastantes veces ayuda a sus hijos en las tareas escolares (frente a un 39,4\% en 2000). Este porcentaje era de poco más del $60 \%$ si el entrevistado tenía estudios superiores y de algo más del $51 \%$ si sus estudios no iban más allá de los primarios completos.

Pese a que el informe de la Conselleria de Cultura de Galicia (2017) considera que las clases particulares no pueden ser consideradas deberes, es altamente probable que una parte significativa de la actividad que realizan las academias -tanto las presenciales como las virtuales- y los profesores particulares consista, en realidad, en ayudar a hacer los deberes. No parece haber estudio alguno que analice este aspecto, pero se puede fácilmente suponer que las clases de, por ejemplo, Matemáticas y Lengua $-y$, en menor medida, de Inglés- se dediquen a ayudar en las tareas. Runte-Geidel (2013) señalaba que el 51\% del alumnado de ESO recibe ayuda para realizar las tareas escolares. Las ayudas son de diferentes tipos tales como ayuda de los propios padres, clases de refuerzo en el propio centro escolar y también clases particulares o en academias privadas. Las clases privadas, particulares o en academias, que reciben los alumnos andaluces de secundaria obligatoria alcanza una cifra cercana al $60 \%$.

De acuerdo con el Instituto Nacional de Calidad y Evaluación (INCE, 2000: 91), este es el porcentaje de alumnos que, a nivel nacional, participaba en actividades extraescolares (en 1995 y 1997):

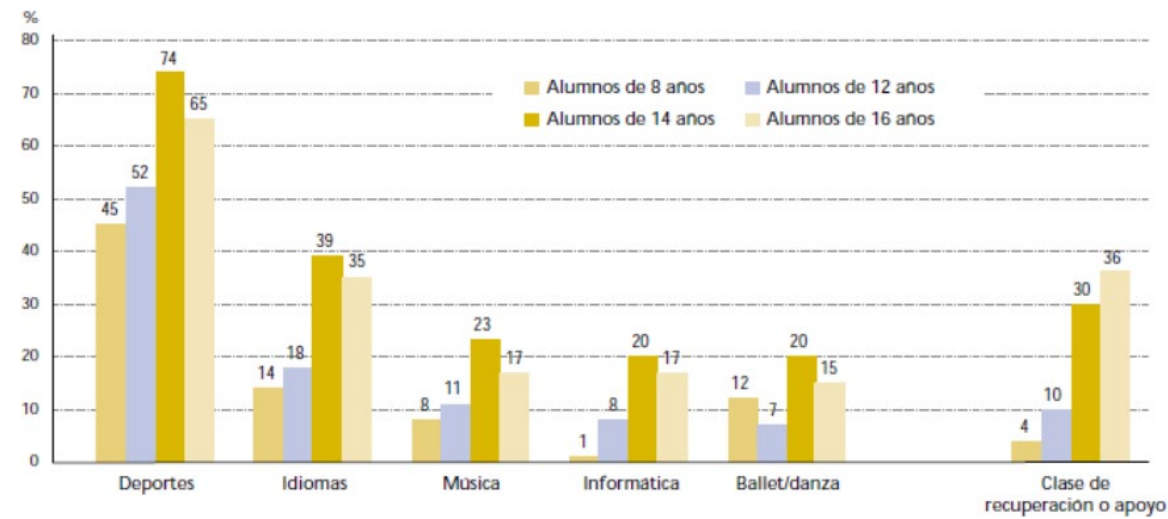

Figura 6

\section{Regulación legal y NORMATIVA}

No existe en el área de la Unión Europea una normativa común sobre los deberes. Según señala Amiama (2013: 8) en su tesis doctoral, algunos países, como 
Dinamarca, aun careciendo de una reglamentación sobre los deberes, cuenta -al menos- con algún tipo de limitación como la de no mandar deberes para los fines de semana (justamente lo que pedía la CEAPA en su campaña nacional). En Francia existen limitaciones que tienen en cuenta la edad del alumnado. En Bélgica, el debate en torno Decreto Nollet (de 2004) puso de manifiesto que los deberes agudizan las desigualdades sociales, fatigan a los menores y son una fuente de tensión familiar.

En el caso de España, y en pleno franquismo, la legislación establecía restricciones con respecto a los deberes. Así, el decreto de 31 de mayo de 1957 señala que "queda prohibido encomendar a los alumnos trabajos para ejecutar fuera del Centro. Los que con carácter excepcional se les encomiende se someterán a la previa aprobación del Jefe de Estudios".

La resolución de 13 de noviembre de 1964 indica, en su exposición de motivos, que en muchos centros de primaria se mandan deberes que "constituyen una sobrecarga para los alumnos quienes a veces se ven obligados a emplear en su realización el tiempo que habrían de dedicar al juego, a la convivencia familiar o incluso al descanso".

El decreto 1106/1967, de 31 de mayo de 1967 establece que "todo el trabajo escolar de los alumnos deberá ser realizado dentro de las horas de las respectivas clases. En consecuencia, ningún Profesor oficial o no oficial podrá encomendar deberes, tareas, estudios o trabajos a los alumnos para su realización fuera de las horas de clase".

Años más tarde, la resolución de 1973 de la Dirección General de Ordenación Educativa dirigida a los Delegados provinciales del Ministerio de Educación y Ciencia e Inspectores-Jefes de Enseñanza Primaria indicaba lo siguiente:

$1^{\circ}$. Los programas de los centros serán elaborados de forma que eviten como norma general el recargo de actividad de los alumnos con tareas suplementarias fuera de la jornada escolar. Cuantitativamente se graduará cuidadosamente este tipo de actividades de forma tal que su intensidad sea inversamente proporcional a las edades respectivas. Cualitativamente, las tareas que se realicen fuera de la clase se ajustarán también a las edades y niveles alcanzados, evitándose el encargo de trabajos mecánicos, pasivos o repetitivos.

$4^{\circ}$. Cuando, como sucede en la segunda etapa de Educación Básica, existan varios profesores para un grupo de alumnos, se buscará la debida coordinación entre los mismos para evitar la sobrecarga de tareas y el consiguiente agobio de los escolares. Los profesores afectados se pondrán de acuerdo respecto a la forma de asignar estos trabajos, debiendo atribuirse al tutor la regulación de los mismos.

Sin duda, este último punto, el de la coordinación entre profesores, es el que se antoja más complicado. A diferencia de lo que ocurre en la Universidad con los créditos europeos (los ECTS), en los que cada uno de ellos equivale a entre 
veinticinco y treinta horas de trabajo por parte del estudiante -contabilizando el tiempo invertido tanto dentro como fuera del aula-, nada similar existe en Primaria o Secundaria. De este modo un alumno se puede encontrar con que un profesor puede mandar una cantidad desaforada de deberes. Como prueba de la dificultad para coordinarse entre los profesores, Solano (2017: 184) narraba la experiencia de su centro de Secundaria. Se entregó a los profesores un documento de compromiso voluntario con relación a los deberes. De 65 docentes lo firmaron 26. Se trata de un compromiso que permite a cada docente plena libertad para seleccionar los grupos a los que no mandaría deberes. Entre otras cosas, en este documento se decía lo siguiente:

Consideramos, además, que los deberes tradicionales, basados generalmente en la repetición mecánica o en faenas sin contexto real, no son una herramienta para mejorar el aprendizaje, sino, más bien, un elemento que deriva fuera del aula el trabajo del alumno, lo que puede suponer, incluso, un agravio para los alumnos que no tienen apoyo fuera de la Escuela. Pensamos que el trabajo se ha de supervisar por el docente y que solo se deberían proponer como deberes aquellas actividades puntuales de búsqueda de información o de motivación complementaria de les tareas del aula.

Más recientemente, y ya en el periodo democrático, una circular de la Dirección General de Educación Básica del curso 1984-85 (citado en El País, 1984) dice lo siguiente:

Se prohíbe encomendar tareas con carácter general, regular y periódico para que los alumnos hagan fuera del centro. Los profesores, padres y alumnos podrán reclamar ante las direcciones provinciales del Ministerio de Educación si consideran que se vulnera este principio.

A partir de aquí, no ha habido ni más legislación ni normativa específica sobre los deberes. De hecho, la vigente LOMCE (Ley Orgánica de Mejora de la Calidad Educativa), señala en su artículo 121.5, al regular el Proyecto educativo de centro, que "los centros promoverán compromisos educativos entre las familias o tutores legales y el propio centro en los que se consignen las actividades que padres, profesores y alumnos se comprometen a desarrollar para mejorar el rendimiento académico del alumnado". Todo apunta a que el proyecto educativo de centro debería ser el documento en el que se especificase la política que con relación a los deberes acuerda cada colegio o instituto.

\section{4. ¿EN QUÉ CONSISTEN Y EN QUÉ DEBERÍAN CONSISTIR LOS DEBERES?}

Por desgracia, no disponemos de ninguna investigación que analice en qué consisten los deberes. Como hemos visto en el informe del Consejo Escolar de CastillaLeón, el alumnado dice, y seguramente acierte, que mayoritariamente proceden de los libros de texto. Nada sabemos sobre la existencia de diferentes tipos de deberes en función de factores tales como su duración, su dificultad, los plazos de entrega, su carácter individual o grupal, etc.

Se puede aventurar, con un mínimo margen de error, que están conectados con el modo en que se enseña y con los contenidos curriculares. Sobre el modo 
en que se enseña, parece que lo que prepondera es el aprendizaje mecánico y repetitivo. En un informe sobre el estado de la educación en las islas Canarias realizado por un equipo de la OCDE (OCDE, 2012: 70) se hacía la siguiente afirmación:

Muchos profesores sólo exigen a sus alumnos que memoricen los contenidos de una asignatura para poder aprobar los exámenes. Este estilo de enseñanza no conlleva la obtención de buenos resultados en el informe PISA ni en la educación en general,

Vergara (2017: 124) contaba de este modo su experiencia como padre:

Abandoné definitivamente las fracciones, el mínimo común múltiplo o las ecuaciones de segundo grado. También el análisis gramatical y las interminables listas de vocabulario en inglés.

Cualquiera que sea madre o padre de un escolar sabe que curso tras curso debe acompañar a su hijo o hija en el entrenamiento de procesos -o memorización de contenidos.

Sin embargo, las cosas no siempre han sido así. Agustín Escolano (2017) narraba su propia experiencia como estudiante que cursó Primaria y Secundaria entre las décadas de los 40 y de los 50 y "recuerda con agrado las tareas encomendadas: coleccionar plantas, memorizar una poesía, ejecutar una plana caligráfica, levantar un croquis de mi casa, buscar el significado de algunas palabras."

Sin necesidad de retrotraerse a tiempos pasados, hay alternativas al tipo de deberes actuales. Por ejemplo, Perrenoud (2004) hablaba de tiempos de trabajo en casa en lugar de deberes, de tal manera que estos tiempos podrían dedicarse a hacer, además de algunas de las prácticas que tradicionalmente concebimos como deberes, actividades como leer libros de todo tipo o artículos de revistas o periódicos, ver vídeos didácticos, etc.

Otra alternativa podría ser la denominada "clase invertida" (flipped classroom), término acuñado por los profesores de Secundaria Jonathan Bergmann y Aaron Sams en su libro sobre esta alternativa escolar (2014) y cuya explicación en vídeo es fácilmente localizable en youtube. Muy resumidamente, la clase invertida consiste en que el alumnado aprende el contenido de cada lección o tema por medio de un vídeo seleccionado -o, como en el caso de estos docentes, preparado por ellos mismos- fuera del horario lectivo de manera que en la sesión siguiente se aclaran los contenidos a partir de las dudas o sugerencias planteadas por los estudiantes.

Tal y como indicaba Vatterott (2009) en su libro sobre las tareas escolares, deberíamos preocuparnos por la calidad de los deberes. El principal problema es que, en general, la formación del profesorado no incluye una preparación sobre esta actividad. Esto es, justamente, lo que planteaban Darling-Hammond e Ifill-Lynch (2006) al hacer varias propuestas que podrían hacer relevantes los deberes para todos los estudiantes. Así, ponían de manifiesto el atractivo que para los alumnos tiene el trabajo por proyectos. 
Los maestros también pueden hacer que los deberes sean más útiles para los estudiantes si asignan un trabajo de clase relevante y atractivo que se base en las ideas de estos, de manera que sean ellos mismos quienes las preparen.

\section{Conclusiones}

La cuestión de los deberes se ha convertido en un tema de intensa polémica en la sociedad española en los últimos años. Muchas familias han expresado públicamente sus quejas contra el exceso de tiempo que sus hijos han de dedicar a estas tareas y, al hilo de tal descontento, se ha planteado la cuestión de la utilidad de los deberes e incluso de si estos deberían existir.

Igualmente controvertidos son los resultados de la investigación científica sobre este tema. Cooper sigue siendo el referente fundamental pese a que su obra cuenta ya con más de diez años de antigüedad. De acuerdo con su análisis -un metaanálisis, en realidad-se observa una moderada correlación entre la realización de deberes y los resultados escolares en Secundaria y escasa en Primaria. Sin embargo, investigaciones más recientes muestran que los deberes son más importantes en Primaria que en Secundaria.

Los datos de investigaciones internacionales como el PISA o el TIMSS ponen de manifiesto que España es de los países en los que sus alumnos -tanto de Secundaria como de Primaria- dedican más tiempo a los deberes. Sin embargo, esto no se traduce en que su rendimiento sea mayor que el de algunos países cuyos alumnos emplean poco tiempo en hacer tales tareas. Pese a ello, las encuestas realizadas a profesores, padres y alumnos muestran que la mayor parte de estos colectivos son partidarios de la existencia de los deberes.

Al igual que ocurre en buena parte de Europa, España carece hoy en día -pero no así en el pasado- de una legislación reguladora -0, más bien, limitadora- de los deberes. Posiblemente, lo deseable, más que un marco legal, es que cada centro diera a conocer por medio de su proyecto educativo su posición con respecto a los deberes.

Las diferentes investigaciones e informes realizados en España muestran que los deberes son mayoritariamente repetitivos, seguramente fruto de un currículo tan reiterativo como extenso.

El profesorado carece de una formación específica sobre los deberes. Estos deberían ser relevantes, de manera que su utilidad fuera captada por el alumnado. A ello hay que añadir la importancia de que los deberes les sean devueltos a los estudiantes con las observaciones oportunas.

Son muchas las alternativas a los deberes actuales, desde lo que Perrenaud Ilama "tiempos de trabajo en casa" a la clase invertida pasando por los trabajos por proyectos -habitualmente propuestos por los alumnos-.

Tal y como señalaban Trautwein y Köller (2003), a pesar de la prolongada historia de la investigación sobre los deberes, el estudio de esta cuestión está lejos de poder explicar qué relación pueda haber entre estos y el rendimiento escolar. La investiga- 
ción aún tiene mucho camino por recorrer. Quizás sería conveniente la realización de estudios cualitativos -más bien de carácter etnográfico- en los que se pudiera analizar exactamente en qué consisten los deberes, que permitieran saber cuántas de estas tareas son ejercicios propuestos por los libros de texto o por las explicaciones del profesorado. Asimismo, una investigación etnográfica que implicara entrar en los hogares permitiría calibrar el grado de interés y de atención que los alumnos y sus familias depositan es estas tareas.

\section{REFERENCIAS BIBLIOGRÁFICAS}

$A B C$ (2017). "Los deberes escolares, la polémica que nunca se acaba entre los distintos estamentos educativos". Recuperado de http://www.abc.es/formacion/ abci-deberes-escolares-polemica-nunca-acaba-entre-distintos-estamentoseducativos-201703021009_noticia.html.

Álvarez, P. (2016). "La mayoría de los españoles cree que hay demasiados deberes escolares". Recuperado de https://politica.elpais.com/politica/2016/10/07/ actualidad/1475865956_738300.html.

Amiama Ibarguren, J. F. (2013). Análisis de los deberes escolares en la E.S.O. y exploración de un espacio colaborativo entre profesorado y familias en la Comunidad Autónoma Vasca. Tesis doctoral.

Arribas Jiménez, M. y Gil Bayo, C. (2017). "Reflexiones del Consejo de Sabios acerca de los deberes escolares." En CAM, Las tareas escolares después de la escuela. Recuperado de http://www.madrid.org/bvirtual/BVCM016364.pdf.

Bailén, E. (2015). Cómo sobrevivir a los deberes de tu hijo. Barcelona: Planeta.

Bergmann, J. y Sams, A. (2014). Flipped Learning. Gateway to Student Engagement. International Society for Technology and Education.

CAM (2017). Las tareas escolares después de la escuela. Recuperado de http://www. madrid.org/bvirtual/BVCM016364.pdf.

CEAPA (2016). Fines de semana sin deberes. Recuperado de https:/www.ceapa.es/ content/noviembre-2016-fines-de-semana-sin-deberes.

Consejo Escolar de Navarra (2015). La opinión de los estudiantes sobre los deberes escolares. Recuperado de https://www.navarra.es/NR/rdonlyres/D096F1EB-B08C4554-82D5-C402A27850AF/221905/230512ed70estudio.pdf.

Cooper, H. (1994). "Homework Research and Policy: A Review of the Literature. Center for Applied Research and Educational Improvement". Recuperado de http:// hdl.handle.net/11299/140536.

Cooper, H. (2007). The Battle Over Homework: Common Ground for Administrators, Teachers, and Parents. Londres: Sage.

Darling-Hammond, L. y Ifill-Lynch, O. (2006). "If They'd Only Do Their Work!". Educational Leadership, 63(5), 8-13. Recuperado de http://www.ascd.org/ 
publications/educational-leadership/feb06/vol63/num05/If-They'd-Only-DoTheir-Work!.aspx.

El País (1984). "La desaparición de los 'deberes', novedad en el curso que hoy empiezan 7.000.000 de escolares". Recuperado de https:/elpais.com/diario/1984/09/17/ sociedad/464220001_850215.html.

Education and Training Committee (2014). "Inquiry into the approaches to homework in Victorian schools". State of Victoria, Australia. Parliamentary Paper. Recuperado de https://www.parliament.vic.gov.au/file_uploads/ETC_Homework_Inquiry_final_ report_PWkrPPVH.pdf.

Escolano, A. (2017). "Genealogía de los deberes". Cuadernos de Pedagogía, 475.

Galloway, M., Conner, J. y Pope, D. (2013). "Nonacademic Effects of Homework in Privileged, High-Performing High Schools". The Journal of Experimental Education, 81(4), 490-510. http://doi.org/10.1080/00220973.2012.745469.

Hallam, S. (2006). "Homework: its uses and abuses". Recuperado de https://content. ncetm.org.uk/itt/sec/KeelePGCEMaths2006/Research/Homework\%20Research/ ReportSusanHallam.pdf.

Hattie, J. (2009). Visible Learning: A Synthesis of Over 800 Meta-Analyses Relating to Achievement. Nueva York: Routledge.

Horsley, M. y Walker, R. (2013). Reforming Homework. Practices, Learning and Policy. South Yarra: Palgrave.

INCE (2000). Sistema estatal de indicadores de la educación 2000. Recuperado de https://www.educacionyfp.gob.es/dctm/ievaluacion/indicadores-educativos/ ind2000.pdf?documentld=0901e72b8011107e

Junta de Castilla-León (2017). Deberes escolares (alumnado de $5^{\circ}$ de primaria y $3^{\circ}$ de ESO). Recuperado de http://www.educa.jcyl.es/es/temas/participacion-educativa/ guia-deberes-escolares-buenas-practicas-ensenanza-basica.

Kohn, A. (2007). The Homework Myth: Why Our Kids Get Too Much of a Bad Thing. Boston: Da Capo Press.

López, J. C. (2016). ¿Por qué los profesores ponemos deberes? Recuperado de https://www.tribunasalamanca.com/blogs/recetas-para-educar/posts/por-que-losprofesores-ponemos-deberes.

Martínez, J. A., Muñoz, F. y Carrión, M. A. (2008). Lengua Castellana y Literatura (4º de la ESO), Madrid: Akal.

Meil, G. (2006). Padres e hijos en la España actual. Barcelona, Fundación La Caixa. Recuperado de https://www.uam.es/personal_pdi/economicas/gmeil/espaniol/ publicaciones/libros/padresehijos.pdf.

OCDE (2012). Sistemas fuertes y reformadores exitosos en la educación. Orientaciones de PISA para las Islas Canarias, España. http://doi.org/10.1787/9789264174788-es. 
OECD (2014). ¿Perpetúan los deberes las desigualdades en educación? Disponible en https://www.mecd.gob.es/dctm/inee/pisa-in-focus/pisa-in-focus-n46-esp.pdf? documentld=0901e72b81dd8668.

Pérez-Díaz, V., Rodríguez, J. C. y Fernández, J. J. (2009). Educación y familia: los padres ante la educación general de sus hijos en España. Madrid: Funcas. Disponible en http://www.asp-research.com/es/node/102.

Perrenoud, P. (2004). Diez nuevas competencias para enseñar. Barcelona: Graó.

Rubio, A., Sanmartín, A. y Rodríguez, E. (2017). Las AMPAs en el sistema escolar español: cómo son, qué necesitan y en qué creen. Madrid: Fundación de Ayuda contra la Drogadicción.

Runte-Geidel, A. (2013). "La incidencia de las clases particulares en España a través de los datos de PISA". Revista Española de Educación Comparada, 21, 249-282. https://doi.org/10.5944/reec.21.2013.7622.

Schleicher, A. (2017). Entrevista para EFE a Andreas Schleicher, director de Educación de la OCDE y principal responsable del informe PISA. Recuperado de https:// www.efe.com/efe/espana/sociedad/director-de-pisa-hay-que-disenar-los-deberespara-no-hacerlos-con-padres/10004-3176288\#.

Solano, T. (2017). "Deberes: la persistencia de la escuela de la memoria en la era de la comunicación". En CAM, Las tareas escolares después de la escuela. Recuperado de http://www.madrid.org/bvirtual/BVCM016364.pdf.

Spatarelu. E. M. (2017). "Evidence on Homework Efficiency in TIMSS Mathematics Achievement". Journal Plus Education, 17(1). https://doi.org/10.1017/ sjp.2015.88.

Sztabnik, B. (2014). "Is Homework Helpful? The 5 Questions Every Teacher Should Ask". Recuperado de https://www.edutopia.org/discussion/homework-helpful5-questions-every-teacher-should-ask.

Trautwein, U. y Köller, O. (2003). "The Relationship Between Homework and Achievement-Still Much of a Mystery". Educational Psychology Review, 15(2), 115-145. http://doi.org/10.1023/a:1023460414243.

Trautwein, U. (2007). "The homework achievement relation reconsidered: Differentiating homework time, homework frequency, and homework effort". Learning and Instruction, 17, 372-388. http://doi.org/10.1016/j.learninstruc.2007.02.009.

Trugeda, G. (2015). "Contra los deberes". Recuperado de https://elpais.com/ elpais/2015/05/19/opinion/1432060931_461186.html.

Uruñuela, P. (2009). "La convivencia en los centros escolares". Cuadernos de Pedagogía, 388, 78-81.

Vatterott, C. (2009). Rethinking Homework: Best Practices That Support Diverse Needs. Association for Supervision \& Curriculum Development. 
Vergara Ramírez, J. J. (2017). “¡No mandes deberes, diseña experiencias de aprendizaje!". En CAM, Las tareas escolares después de la escuela. Recuperado de http:// www.madrid.org/bvirtual/BVCM016364.pdf.

Walker, R. (2012). "Study suggests homework of little value to younger students". Recuperado de http://www.abc.net.au/am/content/2012/s3617243.htm.

Walker, R. (2013). "Toward a More Productive Conversation About Homework". The Atlantic. Recuperado de https://www.theatlantic.com/education/archive/2013/09/ toward-a-more-productive-conversation-about-homework/279877/.

World Health Organization (WHO) (2016). Growing up unequal: gender and socioeconomic differences in young people's health and well-being. Recuperado de http://www.euro.who.int/__data/assets/pdf_file/0003/303438/HSBC-No.7Growing-up-unequal-Full-Report.pdf. 